\title{
Key Enablers of Effective Implementation of TQM in Royal Jet Airways
}

\author{
Moza Tahnoon Al Nahyan and Sherine Farouk Abdel All \\ College of Business Administration, Abu Dhabi University, P.O. Box 59911, Abu Dhabi, UAE \\ Correspondence should be addressed to Sherine Farouk Abdel All; mariam0202@yahoo.com
}

Received 20 April 2017; Accepted 17 August 2017; Published 18 September 2017

Academic Editor: Kwai S. Chin

Copyright (C) 2017 Moza Tahnoon Al Nahyan and Sherine Farouk Abdel All. This is an open access article distributed under the Creative Commons Attribution License, which permits unrestricted use, distribution, and reproduction in any medium, provided the original work is properly cited.

\begin{abstract}
Total quality management (TQM) is a unified management approach that concentrates on the consecutive improvement of processes, products, and methods to surpass client expectations. This paper aims to highlight the advantages of implementing TQM in the airline industry by examining the key enablers of TQM. This study was based on a research model including six factors that were found to have a profound influence in implementing TQM. The data needed for the study was collected with the aid of questionnaires and secondary sources. The study discovered that procedures, policies, and a culture of knowledge transfer were the most significant enablers of successful TQM initiatives in Royal Jet Airways. In order to effectively implement TQM, the study suggests that management should offer appropriate recognition and rewards to employees. This will motivate them to adopt and practice TQM initiatives. Apart from that, management should also arrange seminars or workshops to accustom the employees to the basic procedures and objectives of effective TQM.
\end{abstract}

\section{Introduction}

From the inception of total quality management (TQM) in 1980s, [1], professionals and researchers have discovered the advantages of TQM on organization efficiency and performance. In this globalized economy, we can assess TQM with the help of some key principles. These principles represent the foundation of extraordinary organization that aspires to improve its surveillance in the modern economy [2]. The victory of TQM highly depends upon integration of diverse subsystems of management effectively. Although the principles of TQM are still waxing, they ensure improved services and products [3]. Furthermore, they result in reduction in cost, highly satisfied employees and customers, and improvement in financial performance (see [2] and (Kurt, A., \& Zehir, C., 2016)).

The business world faces extreme competition. In order to stay ahead, businesses have to offer products and services with quality. A product or service of high quality empowers an organization to add and retain customers. The general business scenarios have been proven to be very intricate. This is mainly due to the power that a customer holds in this globalized world. Nowadays, consumers have access to a variety of products and services and they are cognizant of the increasing service. With regard to airline industry, service quality is the kay factor that will differentiate a firm from its competitors. Airlines focusing on the service quality will have a competitive advantage over the others and will eventually prosper. Improper managing of quality will not have any added and assuring value to the airlines [4]. Airlines adopting a strategic approach towards quality management can strengthen their position compared to the competitors [5]. Adopting TQM will ensure that airlines will always focus on customer satisfaction. TQM empowers an employee to take decisions related to his job. Apart from offering a quality service that is safe and affordable, another priority for airlines is to make profit. Here, for attaining maximum effectiveness, the organization should stick to international practices and maintain a system for the management of quality. Aircrafts demand utmost safety and reliability during service use. Further, additional industry-specific requirements should also be taken into consideration. Thus, there is a need to monitor the quality management system and initiate steps for preventing human error [6]. 
This implies that aviation firms like Royal Jet have to implement the principles of total quality management (TQM) with other business strategies to achieve the organizational goals. The present study focuses on identifying the key enablers in executing TQM in Royal Jet Airways.

1.1. Problem Statement. Most organizations around the world utilize total quality management for better performance, to enhance the quality of products/services, and to achieve success. Execution of TQM plays a key part in enhancing the effectiveness of an organization [7]. Nevertheless, TQM implementation may not be always effective and successful. This is because the management mostly considers TQM implementation as tedious, bureaucratic, and unbending [8]. Small organizations are also important for the economy of world. Even now, there are many small organizations that are hesitant to adopt TQM as most of them are skeptical about the outcomes of implementing TQM. A full understanding of the key enablers facilitating TQM will make it very effective.

1.2. Overview of TQM. TQM is a management method that depends on individuals and work procedures. The utmost concern is to improve organizational performance and to enhance client satisfaction. It involves the proper coordination of procedures and methods which will in turn lead to continuous improvement across all business units with the aim of meeting expectations of customers. It emphasizes on maintaining high quality in all areas of an organization. It also aims to reduce rework and waste as it can improve efficiency and lower cost in production. Any organization belonging to any industry or sector can adopt TQM. Even public sector organizations are adopting TQM in order to efficiently meet public demands. However, TQM implementation is hindered in most organizations as they do not adhere to the principles and objectives of TQM. Hence, resorting to a planned blueprint for quality management will improve the competitiveness [5]. This will ensure that the airlines remain customer-focused. Hence, implementing TQM involves buying various units to provide service with enhanced quality [9].

\subsection{Total Quality Management in Aviation Industry. Aviation} industry has managed to provide efficient services with quality, which is not only affordable but also safe. As a way to attain top-notch efficiency, the organization must adhere to the international practices and should implement an information system for maintaining the service quality. TQM principles are very useful for bringing the processes of the company under a sustainable infrastructure for implementing the TQM. There are various aviation industries that implement TQM principles with information system strategy for attaining the organization's goal. TQM tool is considered as a system that is capable of attaining significant business performance. There are various effective TQM tools that improve the process and aid in product variation. This in turn increases operational efficiency.

1.4. Background of Royal Jet Airways. Royal Jet is one of the leading luxury airline services providers based in Abu Dhabi.
Presidential Flight Authority and Abu Dhabi Aviation own the Royal Jet Company. At Royal Jet, client satisfaction is of major importance and they strive to provide an ultimate luxurious experience for the customers. Every aircraft in the Royal Jet fleet has been handpicked to suit a variety of bespoke needs, as per the destination and desires of the customers.

1.5. Royal Jet Key Services. Royal Jet key services are listed as follows:

(i) Luxury VIP aircraft charter

(ii) Charter brokerage

(iii) Fixed base operations (FBO)/VIP terminal at $\mathrm{Abu}$ Dhabi International Airport

(iv) Medical evacuation services

(v) Acquisition consultancy and management of aircrafts

1.6. Implementation of TQM in Royal Jet Airways. Royal Jet Airways focuses on implementing TQM by focusing on the training of employees, managerial effectiveness, and organizational productivity. The top management of Royal Jet Airways believes that excellence in service quality is a philosophy and it is important to have the right corporate culture for attaining good service quality which is made possible through effective internal communication. This is because, through communication, employees can be motivated to understand the aspirations of the organization in a better way. Similarly, external communication also plays significant role, through which the customer gets benefited. One key strategy of Royal Jet is to provide services of high quality. This is made possible by embedding quality in decision-making process, work processes, environment, and teamwork.

There is also a supplier management team with the aim of improving performance of suppliers and purchasing productivity. This team establishes the framework for managing supplier performance designs and coordinates the Supplier Quality Conference and initiates and communicates improvements to the supplier management process.

As a service organization, Royal Jet Airways strives to maintain the quality of services it has been offering. It has a customized supplier performance management approach model, where it allows buying units for ascertaining which suppliers deliver the requirements consistently. In addition, Royal Jet Airways supplier performance management process involves measures and feedback to assist suppliers in understanding what they need to perform so as to earn more business.

Further, top management strongly believes in the need to deliver quality service. They also believe in continuous improvement. During the previous three years, Royal Jet has been focusing on redefining the quality standards intending to be one of the leading airlines with regard to service and safety.

\section{Literature Review and Hypotheses}

Quality is an essential component of success in this globalized world and every organization has to take suitable measures to 
produce products and services of high quality. Demirbag et al. (2006) [10] named total quality management as philosophy of management and universal approach which pursues the continuous improvement in operations and functions of an organization to make products and/or to deliver services that satisfy consumer necessities. Kaur et al. [11] termed TQM as an approach to increase the quality of an organization's output to satisfy the demands of consumers. This results in a prolonged success [12]. TQM was originally meant for manufacturing sector but has gained a staggering reputation as a key factor of competitive advantage in service sector as well. Thus, TQM addresses the entire framework of business by responding to the needs of every stakeholder [13].

Islam and Haque [14] stated that TQM depends on 6 elements, namely, generation of quality management, teamwork enhancement, practicing quality control techniques and tools, customer relationship, supplier relationship focus, and employee performance, and argued that top management must ensure that TQM execution is effective in an organization.

Chen and $\mathrm{Hu}$ [15] attempted to investigate the determinants of airline passenger loyalty in the high frills Indonesian airline industry. 250 respondents, that is, Indonesian airline passengers, were selected for collecting data. The study findings reflect that customer engagement has the most influential effect on passenger loyalty, followed by customer satisfaction. Service quality, client satisfaction, and perceived value also impact customer loyalty.

According to a study by Kim [16], the importance of relationship between total quality management and client satisfaction was displayed. This study implemented quantitative methodology for gathering information. The research showed that TQM implementation helps in attaining a stand over the competitors, which increases performance.

A research was conducted by Mahmood et al. [17] to measure performance through TQM. The research was related to the aviation industry in Pakistan. The result of the research was crucial in creating a TQM measuring tool which aided decision-makers to evaluate the performance of any aviation manufacturing organization in Pakistan.

Misopoulos et al. [18] conducted a study of the Twitter handling for identifying critical elements for customer service in the airline sector. The purpose of the study was to analyze customer services through Twitter comments. This study implemented the method of sentiment analysis. Thus, 67,953 twitter comments were analyzed to assess the sentiments of customers regarding the services provided by four airline companies. The study uncovered positive and negative client assumptions and sentiments. It showed that most of the positive sentiments were related to online and mobile checkin services, reasonable prices, and flight experiences, whereas negative sentiments were related to usability of web sites, delay in flights, and lost luggage. Further, it was identified that customers experienced delightful services provided at airport lounges [18].

Suki [19] conducted a study to understand the effects of airline service quality in terms of airline tangibles, customer satisfaction, and terminal tangibles. Convenience sampling was utilized to choose 300 respondents travelling through either Malaysia Airlines or Air Asia as a part of data collection procedure. Data analysis was done by using statistical methods. The study findings showed that "word-of-mouth" recommendations worked wonders for customer satisfaction which was dependent on quality.

A study conducted by Baker [20] examined customer satisfaction and service quality of the US airlines. The study illustrated that there was a significant variation even though the traditional carriers are leaning towards a higher level of service quality. Further, the service quality of low-cost airlines was seen to be higher than that of traditional airlines.

According to Guangming et al. [21], the main aim of any organization is to satisfy the consumer needs by offering services and products as required, with the help of TQM. However, Pakistan International Airlines did not focus much on customer satisfaction. Hence, PIA faced many obstacles and challenges. Gunasekaran [22] stated that resources, equipment, and quality management methods are supplied by TQM for the continuous enhancement of quality, which will lead to customer satisfaction.

Singh and Sushil [23] lead a research to assess and gauge the interactions of various enablers of TQM. The study was based on domestic airline industry of India. This study implemented ISM and TISM methods. The study findings identified that aspects like hierarchy, training, improvement on progressive basis, and employee involvement and commitment on the higher level make a significant impact at the bottom of this model. On the other hand, the outcome variables of TQM yield low driving power accompanied with high dependence power. Thus, by implementing TISM model, Indian airline industry would become more productive and competitive, which eventually would lead to earning maximum profit.

A research was done by Arif et al. [24] to assess the tools and methods used by the United Arab Emirates' (UAE's) federal government to enhance customer satisfaction in the aviation industry. This study took into account customer service being rendered at three airports. 78 respondents were selected by the random sampling method and their feedback was collected. Chi-square test was used for data analysis. The study findings revealed public opinions regarding various innovative measures implemented by UAE government [24].

A study was done by Chen and $\mathrm{Hu}$ [15] to assess the relational advantage between two aspects: service quality and customer loyalty. Data was collected from 403 respondents for this study. The study revealed that service quality had a significant impact on customer loyalty. Moreover, service quality also made an impact on loyalty of customers involving customer relational benefits.

2.1. Important Factors of Total Quality Management. The following are considered as the key factors affecting TQM in any organization.

2.1.1. Leadership. Leadership has a profound influence in TQM implementation. Managers should dedicate their efforts to leading and motivating the employees so that they can effectively implement TQM. Here, managers need to 
understand the TQM policies and implement them in the right perspective. The management must ensure that TQM values, strategies, and goals should be transmitted to all the levels of the organization. There are certain practices of TQM which differ from one organization to another due to differing nature of work. Nevertheless, there is common acceptance regarding the importance of leadership by higher management while implementing TQM.

Leadership is of extreme importance in TQM as it provides a vision. Total quality can be achieved through continuous improvement and it brings about success of the organization. Continuous improvement can be attained through motivated employees who work together and utilize productive tools for increasing user satisfaction. Leaders can ensure that they motivate the employees. Leaders should concentrate on service-orientated attitude and continuous learning and should trust other people of the organization because TQM is people-oriented. TQM facilitates success through continuous improvement. Continuous improvement can be attained through motivated employees.

2.1.2. Training and Education. TQM revolves around employee empowerment and motivation, which requires some important skills and knowledge. This aspect could be gained through training. However, there are some steps that need to be adhered to to ensure effective training. The first and most important step in training is to make everyone understand the need and value for training and then finally implement the program.

There is another key aspect of total quality management training and that is for the employees to understand the vision and mission of the corporate. Although CEOs and governing boards are responsible for ensuring optimum performance in place, they depend on individual employees and their involvement in TQM knowledge transfer to implement corporate procedures and policies [25].

2.1.3. Knowledge Management. Knowledge management is considered as continuous improvement; on the contrary, TQM is viewed as radical improvement and both are compatible with each other [26]. As per the study by Hsu and Shen [26], KM exists in parallel with TQM, since both have the same features such as results orientation, teamwork, peoplebased management, leadership, and meeting the needs of customer. A study was performed by Ju et al. [27] to examine the practical dimension of KM and TQM. It was identified that KM is highly interconnected to TQM, and it positively contributes to TQM [27].

2.1.4. Teamwork. Teamwork and collaboration are a vital part in accomplishing organizational goals, which in turn makes teams and groups an important part of any TQM effort [28]. According to Stough et al. [29], working in a group is more beneficial than working individually. Business will be able to attain efficient solutions to problems by working in teams. This will also enable people to be at ease when working in teams, which will help them to communicate openly and freely.
2.1.5. Communication. A communication model will result in reduced ambiguity and fear and will allow TQM to be implemented faster. Deming [1] stated that the top management and employees should overcome the fear of change. Good feedback and communication system are vital in expressing ideas to the management. According to Saylor [30], the best ways of communications are direct communication between employees and supervisors and face-to-face communication.

2.1.6. Customer Focus. The extent to which firms go to in order to satisfy customers is called customer focus. A successful firm understands the need to always give first place to the customer. The quality management key is in maintaining a close relationship with the customer. The customer should be closely involved in all stages in order to completely identify customer needs. According to Saylor (1996), the focus on customer is one of the key elements of TQM as customers allow an organization to exist.

2.1.7. Employees Involvement and Participation. If the workforce is dedicated and has the requisite skill, then TQM could be implemented successfully. Hence, all the employees from higher to lowest level must be encouraged to own up the responsibility and communicate effectively for improving the quality at all the stages. All employees working in an organization should be considered as internal customers and must be satisfied, if the organization wants to ensure full satisfaction to its external customers. This is the scenario, where customers and suppliers are closely related to both external and internal customers.

2.1.8. Perception of Quality. The association between service quality and client satisfaction in service sectors was studied by Kaur et al. (2010). Convenience sampling was used to select the respondents. This study used data from Umea University, Forex, and ICA and analysis was done by using SERQUAL model. The study observed the positive relationship between service quality and customer satisfaction. The service quality in airline sectors was assessed (Verma [31]). The research was done to assess the impact of the quality of service on client satisfaction. It showed that client satisfaction is highly related to quality services and products.

2.1.9. Quality Control in Organization. Tharmarajah [32] examined the effect of TQM implementation to increase the competiveness of airline industry. He stated that, due to the size, complexity, and nature, the airline sector needed to implement TQM practices. Thus, the study adopted the Six Sigma quality control principle. The study adopted the secondary data collection method. The study findings indicated that various advantages were achieved after implementing TQM, which included operational effectiveness and customer satisfaction. In addition, the study identified that TQM's fundamental role is to provide services that make the customers satisfied.

2.2. Obstacles in Implementing TQM. This section identifies the obstacles involved in TQM implementation. The effect of 


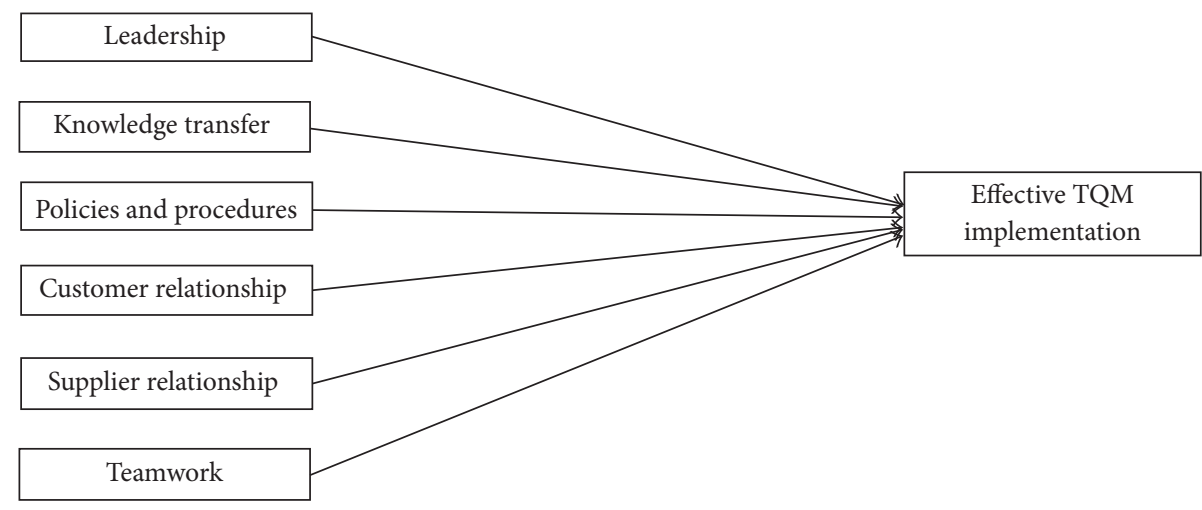

FIGURE 1: Conceptual model for TQM enabling factors in an airline industry.

TQM on various performance indicators was demonstrated by the study conducted by Sadikoglu and Olcay [33]. It also studied the barriers and issues of the TQM practices on organizations in Turkey. This study showed that the outcomes of organizational performance were greatly influenced by TQM practices. It was revealed that the primary obstacle faced by companies in Turkey was the inappropriate firm structure and lack of employee engagement.

Talib and Rahman [34] studied and differentiated the impediments of successful TQM implementation in the service sector. The paper assessed TQM barriers and prioritized their relevance in the service industry. According to the research, "managerial issues" were found to be the most important impediment followed by "people-oriented issues" and "organizational issues." The results have also shown that "lack of communication" impediment was the most important among all the other barriers. The least significant impediment was "lack of coordination between departments."

Singh and Ahuja [35] identified the main issues in TQM implementation which include lack of knowledge and awareness about TQM, unfavorable industrial relation, poor customer relationship, and lack of control of quality and survey. In addition, some other obstacles were the lack of continuous self-assessment, attitude, and culture of management, limited number of employees in recruitment process, human resource problem, financial constraints, and so forth.

2.3. Conceptual Model of the Study. The conceptual model of the study was designed after an extensive literature review. And this is used for the second part of the study to analyze the most critical factor in TQM implementation. Figure 1 represents this model.

2.4. Hypotheses. Based on the literature review, the following hypotheses were constructed for the analysis:

(H1) There is a significant relationship between the TQM knowledge dimensions.

(H2) There is a significant relationship between the data acquisition dimensions.

(H3) There is a significant relationship between the training dimensions
(H4) There is a significant relationship between top management commitments

(H5) There is a strong relationship between quality control dimensions.

\section{Research Methodology}

This study explores and illustrates two aspects of TQM which are highly interconnected. The first aspect is the effective TQM implementation and the second aspect is analyzing the key enabling factors of TQM. The study was conducted in Royal Jet Airways.

3.1. Sample Selection. The study was conducted by taking a sample size of 300 respondents, out of which 150 are quality assurance managers and 150 are technicians working in Royal Jet Airways. Convenience method of sampling was chosen to obtain the respondents required for the study.

3.2. Data Collection. The airlines sector was chosen for this study as it is a rapidly burgeoning industry and the various players in this industry are constantly trying to establish themselves by providing excellent high-quality service and comfortable and efficient operations by implementing TQM. Secondary data was collected to identify the descriptive information from websites, articles, newspapers, magazines, and so forth.

3.3. Survey Instrument. Primary information was collected by using a survey. Based on the convenience of quality managers and technicians, a questionnaire was distributed via email. A 5-point Likert scale was implemented in the questionnaire by which the participants were asked to reply to the questions through a certain range of answers that initially begin with "strongly agree" and end with "strongly disagree." The remaining questions were multiple choice and open-ended questions. The gathered data was analyzed by chi-square tests.

\section{Analysis and Results}

This study undertakes two main objectives; the first objective is to understand and study the various factors that facilitate 
effective implementation of TQM and the second objective is to investigate and understand the key factors enabling TQM implementation. To obtain the required data for the analysis, the technicians and quality assurance managers are asked to examine the level of effectiveness in implementing managerial practices of TQM in Royal Jet Airways. The questionnaire was developed to generate data about quality management practices in Royal Jet Airways. The developed questionnaire was based on the following six sections which had various factors:

\section{(i) Participant's knowledge about TQM}

(ii) Data acquisition methods utilized by the organization

(iii) Perception of quality

(iv) Level of training given to the employees towards TQM

(v) Quality control

(vi) Challenges faced in executing TQM

Each of these six sections is comprised of several factors and a two-part analysis is done to understand which among these factors plays a key role in the effective implementation of TQM. The first part is an in-depth study of the significance of each factor in these six sections in implementing effective TQM. The second part gauges which are the key enabling factors for effective TQM.

Chi-square analysis is done to analyze the data. This method is used to determine if there is a significant relationship between the variables chosen for the study. The strength of the relationship can be understood by looking at the chisquare value and the $p$ value.

4.1. Results. The results and analysis of the quantitative data are presented in this section. The data was collected from the top-level positions in Royal Jet, UAE. The sample size taken for the study is $n=300$. The data was first entered into an Excel file and then exported into SPSS version 20.0 and study results were analyzed. The gathered information was analyzed using the chi-square values, percentage, and frequency, with the level of significance taken as 0.05 .

Table 1 presents the demographic characteristics of the respondents. 300 respondents belong to aviation/air transport company, from which the average (100) respondents are from admin and average 200 respondents are from technical departments. The majority $(180,60 \%)$ of respondents opined that annual turnover is $>$ US $\$ 500 \mathrm{~m}$ and $120(40 \%)$ respondents were of the opinion that the annual turnover is $<\mathrm{US} \$ 500 \mathrm{~m}$. Among the respondents, $50 \%$ were from quality assurance and $50 \%$ were directors and technicians.

(H1) There Is a Significant Relationship between the TQM Knowledge Dimensions. Table 2 presents the ranking of knowledge of TQM: "teamwork" received the first rank as its chi-square value reached 8.533 and as a result there is significant relationship, whereas the second rank was given to "value of money" as its chi-square value reached 1.200 and is insignificant. "Satisfying internal customer (within the
TABLE 1: Descriptive statistics.

\begin{tabular}{lc}
\hline Characteristics & $n(\%)$ \\
\hline Status of the company & $300(100)$ \\
Aviation/air transport & \\
Size of the firm & 100 \\
Admin & 200 \\
Technical & \\
Annual turnover & $120(40 \%)$ \\
$<$ US\$500m & $180(60 \%)$ \\
$>$ US\$500m & $11(12,10)$ \\
Age of the firm (years) & \\
Position of the respondents & $150(50 \%)$ \\
Quality assurance director & $150(50 \%)$ \\
Technician &
\end{tabular}

organization)" obtained the third rank as its chi-square value reached 0.533 and is insignificant. The fourth rank was given to "increased profit" as its chi-square value reached 0.133; the fifth rank was for "satisfying external customer (outside the organization)" as its chi-square value reached 3.333. The sixth rank was obtained by two statements: "high cost (expensive)" and "partnership between organization and supplier" as the chi-square value reached 4.800 and is significant; and, finally, "appearance" obtained the seventh rank as its chi-square value reached 6.533 , showing that the statement is significant.

(H2) There Is a Significant Relationship between the Data Acquisition Dimensions. Table 3 presents the significance of data acquisition method: "are employees empowered to make significant changes to construction operations or methodology?" was ranked first as its chi-square value reached 8.533; as a result there is significant relationship with answers by respondents,; the second rank was given to "do you have a system for gathering clients suggestions?" as its chisquare value reached 3.800 and is insignificant. "Are suppliers/subcontractors rated?" obtained the third rank as its chisquare value reached 3.800 and is insignificant. The fourth rank was given to "how do you measure client's satisfaction?" as its chi-square value reached 8.533; the fifth rank was for "if defects in service are identified, then are subcontractors required to pay for correct team?" as its chi-square value reached 7.400. The sixth rank was given to "do you have a system for gathering employees suggestions/exit interviews?" as its chi-square value reached 6.533; the seventh rank was for "do you collect data to measure the performance of operations or process?" as its chi-square value reached 4.800 and is significant; and, finally, "how does your organization solve quality related problems?" obtained the eighth rank as its chi-square value reached 8.533 , showing that the statement is significant.

(H3) There Is a Significant Relationship between the Training Dimensions. Table 4 presents the significance of training: "is formal training in TQM or other quality improvement philosophies given to employees?" got the first ranking as the chi-square value is 12.20 , which showed that there is a 
TABLE 2: Ranking of dimension of knowledge of TQM by using chi-square value.

\begin{tabular}{lcccc}
\hline $\begin{array}{l}\text { Which of these words best } \\
\text { define quality? }\end{array}$ & Mean & Ranking & Chi-square & $p$ value \\
\hline Teamwork & 0.77 & 1 & 8.533 & $0.003^{* *}$ \\
$\begin{array}{l}\text { Value for money } \\
\text { Satisfying internal customer } \\
\text { (within the organization) }\end{array}$ & 0.60 & 2 & 0.533 & 0.273 \\
Increased profit & 0.57 & 3 & 0.133 \\
Satisfying external customer & 0.53 & 4 & 3.333 \\
(outside the organization) & 0.33 & 5 & 4.800 & 0.465 \\
High cost (expensive) & 0.30 & 6.5 & 4.800 & 0.068 \\
Supplier relationship & 0.30 & 6.5 & 6.533 & $0.028^{*}$ \\
Appearance & 0.27 & 8 & $0.028^{*}$ \\
\hline
\end{tabular}

${ }^{* *} p<0.01 ;{ }^{*} p<0.05$.

TABLE 3: Significance of dimensions of data acquisition method by using chi-square value.

\begin{tabular}{|c|c|c|c|c|}
\hline Dimensions/variables & Mean & Ranking & Chi-square & $p$ value \\
\hline $\begin{array}{l}\text { Are employees empowered to make } \\
\text { significant changes to construction } \\
\text { operations or methodology? }\end{array}$ & 2.47 & 1 & 8.533 & $0.003^{* *}$ \\
\hline $\begin{array}{l}\text { Do you have a system for gathering } \\
\text { clients suggestions? }\end{array}$ & 2.27 & 2 & 3.800 & 0.150 \\
\hline Are suppliers/subcontractors rated? & 2.03 & 3 & 3.800 & 0.150 \\
\hline $\begin{array}{l}\text { How do you measure customer } \\
\text { satisfaction? }\end{array}$ & 1.77 & 4 & 8.533 & $0.003^{* *}$ \\
\hline $\begin{array}{l}\text { If defects in service are identified, then } \\
\text { are subcontractors required to pay for } \\
\text { correct team? }\end{array}$ & 1.63 & 5 & 7.400 & $0.025^{*}$ \\
\hline $\begin{array}{l}\text { Do you have a system for gathering } \\
\text { employees suggestions/exit interviews? }\end{array}$ & 1.53 & 6 & 6.533 & $0.011^{* *}$ \\
\hline $\begin{array}{l}\text { Do you collect data to measure the } \\
\text { performance of operations or process? }\end{array}$ & 1.30 & 7 & 4.800 & $0.028^{*}$ \\
\hline $\begin{array}{l}\text { How does your organization solve quality } \\
\text { related problems? }\end{array}$ & 1.23 & 8 & 8.533 & $0.003^{* *}$ \\
\hline
\end{tabular}

${ }^{* *} p<0.01 ;{ }^{*} p<0.05$.

TABLE 4: Significance of training dimensions by using chi-square value.

\begin{tabular}{lcccc}
\hline Dimensions/variables & Mean & Ranking & Chi-square & $p$ value \\
\hline $\begin{array}{l}\text { Is formal training in TQM or other } \\
\text { quality improvement philosophies given } \\
\text { to employees? }\end{array}$ & 2.43 & 1 & 12.200 & \\
Training currently emphasizes & & & $\mathbf{0 . 0 0 2}^{* *}$ \\
Data gathering \& analysis & 0.77 & 2.5 & 8.533 \\
Teamwork & 0.77 & 2.5 & 8.533 & $\mathbf{0 . 0 0 3}^{* *}$ \\
Communication & 0.73 & 4 & 3.333 & $\mathbf{0 . 0 0 3}^{* *}$ \\
Customer satisfaction & 0.67 & 5 & 2.133 & 0.068 \\
Others & 0.63 & 6 & 16.133 & 0.144 \\
Process control & 0.13 & 7 & 19.200 & $\mathbf{0 . 0 0 0}^{* *}$ \\
Statistical analysis & 0.10 & 8 & $\mathbf{0 . 0 0 0}^{* *}$ \\
\hline
\end{tabular}

** $p<0.01$. 
TABLE 5: Significance of top management dimensions by using chi-square value.

\begin{tabular}{lccc}
\hline Variable & Mean & Ranking & Chi-square \\
\hline $\begin{array}{l}\text { Top management } \\
\begin{array}{l}\text { Does your quality improvement plan have the full } \\
\text { support of top management? }\end{array}\end{array}$ & 1.57 & 1 & 9.800 \\
${ }^{* *} p<0.01$. & & $\mathbf{0 . 0 0 7}^{* *}$ \\
\hline
\end{tabular}

TABLE 6: Significance of quality control dimensions by using chi-square value.

\begin{tabular}{lccc}
\hline Variables & Mean & Ranking & Chi-square \\
\hline $\begin{array}{l}\text { What type of quality improvement } \\
\text { program do you have? }\end{array}$ & 2.27 & 1 & 6.533 \\
$\begin{array}{l}\text { Does your organization have a quality } \\
\text { improvement program? }\end{array}$ & 1.53 & 2 & 0.133 \\
$\begin{array}{l}\text { Your organization's quality improvement } \\
\text { can be described as }\end{array}$ & 1.33 & 3 & $0.011^{* *}$ \\
$\begin{array}{l}\text { Has your organization developed a clear } \\
\text { quality policy? }\end{array}$ & 1.30 & 4 & 0.715 \\
${ }^{* *} p<0.01{ }^{*} p<0.05$ & & & 0.068 \\
\end{tabular}

significant relationship with answers by respondents, whereas the second rank was given to "data gathering \& analysis" and "teamwork" and they have the same rank as the chi-square value reached 8.533 and is significant. The third rank was for "communication" as its chi-square value reached 6.533; the fourth rank was for "customer satisfaction" as its chisquare value reached 3.333. The fifth rank was for "others" as its chi-square value reached 2.133; the sixth rank was for "process control" as its chi-square value reached 16.133 and is significant; and, finally, "statistical analysis" obtained the seventh rank as its chi-square value reached 19.200, showing that the statement is significant.

(H4) There Is a Significant Relationship between Top Management Commitments. Table 5 presents the significance of top management: "does your quality improvement plan have the full support of top management?" received the first ranking as its chi-square value reached 9.800; as a result, there is significant relationship with answers by respondents.

(H5) There Is a Strong Relationship between Quality Control Dimensions. Table 6 presents the significance of quality control dimensions: "what type of quality improvement program do you have?" was ranked first as its chi-square value reached 6.533 , which showed that there is a significant relationship with answers by respondents, whereas the second rank was occupied by "does your organization have a quality improvement program?" as its chi-square value reached 0.133 , which showed that it is insignificant. "Your organization's quality improvement can be described as" obtained the third rank as its chi-square value reached 0.333 , which showed that it is insignificant; and, finally, "has your organization developed a clear quality policy?" obtained the fourth rank as its chi-square value reached 4.800 , which proved that the statement is significant.

Figure 2 represents the obstacles in the implementation of TQM: $100 \%$ of the respondents answered "tendency to cure

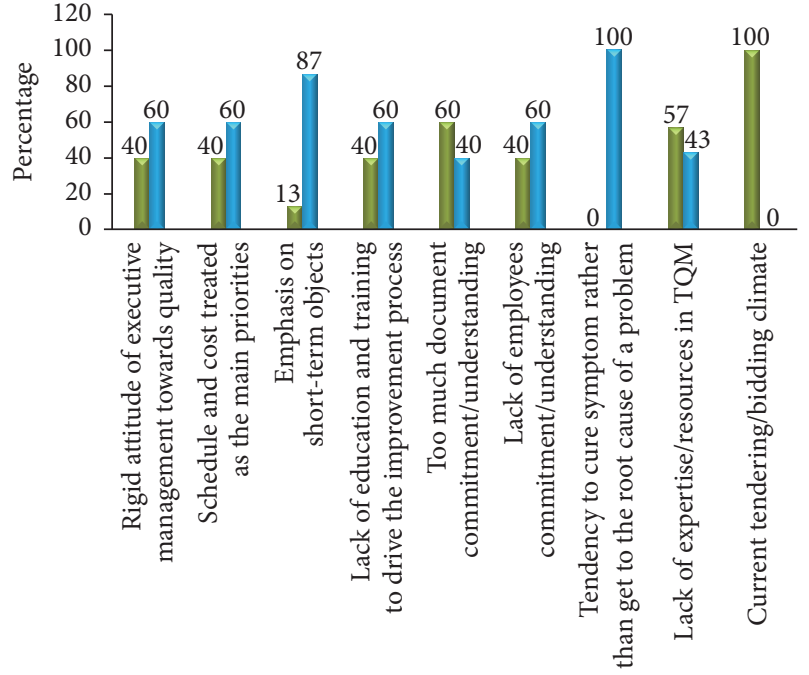

Obstacles in the implementation of TQM program

回 No

口 Yes

FIgURE 2: Obstacles in the implementation of TQM program.

symptom rather than get to the root cause of a problem"; $87 \%$ answered "emphasis on a short-term objects" and $43 \%$ answered "lack of expertise/resources in TQM."

Table 7 shows the detailed results with respect to each of the six factors. The term "average" refers to the mean score for a given factor from the 61 responses. "Variance" reflects the degree of dissimilarity in the responses. "Weight" was calculated by dividing the average response to a given factor by the sum of the average responses of all factors.

Figure 3 shows the factor weights in graphical form, which illustrates the extent to which each of the six factors was an enabler of TQM initiatives in the industry. 
TABLE 7: Impact of enabling factors on TQM.

\begin{tabular}{lcccccc}
\hline & Leadership & Procedures & Knowledge & Supplier & Customer & Teamwork \\
\hline Average & 3.01 & 3.48 & 3.65 & 2.83 & 3.27 & 3.09 \\
Variances & 1.44 & 1.16 & 0.87 & 0.76 & 1.22 & 0.73 \\
Weightage & 0.17 & 0.19 & 0.18 & 0.16 & 0.18 & 0.17 \\
\hline
\end{tabular}

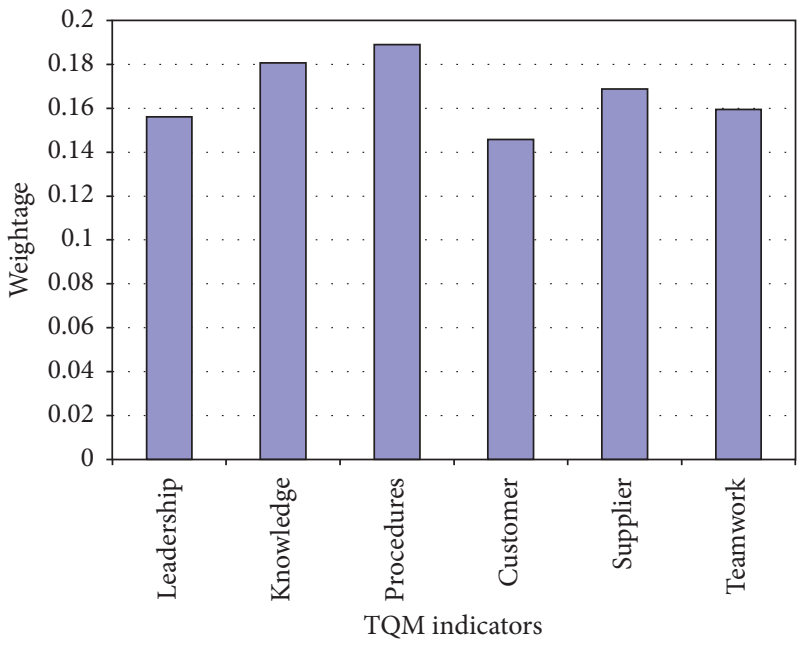

FIGURE 3: Weights of enabling factors to TQM initiatives.

It is apparent from Figure 3 that procedures and policies and knowledge transfer are perceived to be the most significant enablers of successful TQM implementation in Royal Jet. Leadership, teamwork, and supplier relationship were of secondary importance as enablers. Customer relationship was considered to be the least significant enabler of the success of TQM initiatives.

\section{Discussion, Managerial Implications, and Conclusions}

5.1. Discussion. The study revealed that procedures and policies were the most significant enablers of the success of TQM initiative in an airline industry. The second most significant enabler of successful TQM initiatives was the dissemination of information and incentives for knowledge sharing. A major part of the respondents felt that there was a need for a suitable system in their organizations to organize knowledge logically. The implementation of a suitable system would enable the employees to share their experience through a unified interface platform accessible to all interested members of an organization.

Relationship with suppliers and subsuppliers was the third most significant enabler of TQM initiatives, while teamwork among employees and departments was the fourth most significant one. It is clearly understood that coordination with suppliers to acquaint them with the aims and procedures of TQM would increase the possibility of success of the TQM initiatives. The results also recommend that the top management should put forward appropriate incentives to encourage the employees to accept and adopt TQM initiatives.

This signifies the role of leadership as the fifth significant factor. Leadership is a critical factor for a successful TQM initiative. A culture of support and encouragement urges the employees to convey and share common knowledge and information. This in turn improves the possibility that employees will communicate in an effective manner to attain their common goals. Finally, relationship with customers was the last significant enabler of the success of TQM initiatives. It is likely that the respondents perceived customers as an external entity and thus have overlooked the need for involving customers' input and feedback into their TQM initiatives. However, the senior leadership should clearly encourage the involvement of customers.

5.2. Managerial and Policy Implications. This study has examined the important success factors for TQM initiatives in Royal Jet. The results of this study have several important inferences for the quality managers who aim to implement successful TQM methods in their organization. The study suggested that leadership has to come up with appropriate incentives to motivate the employees to engage in TQM. Such an incentive package will also encourage workers to suggest new ideas for effective TQM implementation. The leadership should also arrange workshops and seminars to accustom employees to the basic methods and procedures of TQM, as it is clear that employees will not be able to contribute meaningfully to TQM unless they are acquainted with the methods and processes that it involves. It was also understood that implementing TQM without the coordination of suppliers and customers is more than difficult; it is nearly impossible. Finally, management should foster an organizational culture that encourages teamwork in TQM initiatives and should assist all the employees to perform their tasks effectively.

5.3. Conclusion. This study analyzed the key factors that enable successful implementation of TQM. After an extensive study of the relevant literature, a suitable questionnaire was designed to collect the data. The collected data was analyzed and results were studied. The results showed that the most critical factors affecting TQM implementation were the culture of knowledge transfer, policies, and procedures. This was followed by leadership, teamwork, and other factors. This concluded that these factors can help to implement TQM in an effective way.

\section{Conflicts of Interest}

The authors declare that there are no conflicts of interest regarding the publication of this article. 


\section{References}

[1] W. Deming, Out of the Crisis MIT Center for Advanced Engineering, Cambridge University Press, Cambridge, UK, 1986.

[2] Rigby. and B. Bilodeau, Management Tools \& Trends 2015, Bain \& Company, London, UK, 2015.

[3] R. Al-Ettayyem and M. Zu'bi, "Investigating the effect of total quality management practices on organizational performance in the jordanian banking sector," International Business Research, vol. 8, no. 3, article 79, 2015.

[4] V. J. Peters, “Total service quality management," Managing Service Quality: An International Journal, vol. 9, no. 1, pp. 6-12, 1999.

[5] A. Ghobadian, S. Speller, and M. Jones, "Service quality concepts and models," International Journal of Quality \& Reliability Management, vol. 11, no. 9, pp. 43-66, 1994.

[6] B. Lazur, I. Jagadeesh, Karthikeyan., and M. Shanmugaraja, "An initiative to practice total quality management in aircraft maintenance," Advances in Aerospace Science and Applications, vol. 3, no. 2, pp. 63-68, 2013.

[7] Z. Zhang, A. Waszink, and J. Wijngaard, "An instrument for measuring TQM implementation for Chinese manufacturing companies," International Journal of Quality and Reliability Management, vol. 17, no. 7, pp. 730-755, 2000.

[8] J. S. Oakland, Total Quality Management - The Route to Improving Performance, Butterworth-Heinemann Ltd, Oxford, UK, 1993.

[9] Oluwatoyin. and A. Oluseun, Total Quality Management: A Test of the Effect of TQM on Performance and Stakeholder Satisfaction, Blekinge Institute of Technology, Karlskrona, Sweden, 2008.

[10] M. Demirbag, E. Tatoglu, M. Tekinkus, and S. Zaim, "An analysis of the relationship between TQM implementation and organizational performance: evidence from Turkish SMEs," Journal of Manufacturing Technology Management, vol. 17, no. 6, pp. 829-847, 2006.

[11] M. Kaur, K. Singh, and I. S. Ahuja, "An evaluation of the synergic implementation of TQM and TPM paradigms on business performance," International Journal of Productivity and Performance Management, vol. 62, no. 1, pp. 66-84, 2013.

[12] M. Sharma and R. Kodali, "TQM implementation elements for manufacturing excellence," TQM Journal, vol. 20, no. 6, pp. 599621, 2008.

[13] Shahin, "An investigation on the influence of total quality management on financial performance the case of Boutan Industrial Corporation," International Journal of Business and Social Science, vol. 2, no. 15, 2011.

[14] A. Islam and A. M. Haque, "Pillars of TQM implementation in manufacturing organization - an empirical study," Journal of Research in International Business and Management, vol. 2, no. 5, pp. 128-141, 2012.

[15] P.-T. Chen and H. Hu, "The mediating role of relational benefit between service quality and customer loyalty in airline industry," Total Quality Management and Business Excellence, vol. 24, no. 9-10, pp. 1084-1095, 2013.

[16] G. S. Kim, "Effect of total quality management on customer satisfaction," International Journal of Engineering Sciences \& Research Technology, vol. 5, no. 6, pp. 507-514, 2016.

[17] K. Mahmood, I. M. A. Qureshi, and A. Nisar, "An empirical study on measurement of performance through TQM in Pakistani aviation manufacturing industry," International Journal of
Quality and Reliability Management, vol. 31, no. 6, pp. 665-680, 2014.

[18] F. Misopoulos, M. Mitic, A. Kapoulas, and C. Karapiperis, "Uncovering customer service experiences with Twitter: the case of airline industry," Management Decision, vol. 52, no. 4, pp. 705-723, 2014.

[19] N. M. Suki, "Passenger satisfaction with airline service quality in Malaysia: A structural equation modeling approach," Research in Transportation Business and Management, vol. 10, pp. 26-32, 2014.

[20] D. M. Baker, "Service quality and customer satisfaction in the airline industry: a comparison between legacy airlines and lowcost airlines," American Journal of Tourism Research, vol. 2, no. 1, pp. 67-77, 2013.

[21] C. Guangming, S. Clarke, and B. Lehaney, "A systemic view of organisational change and TQM," TQM Magazine, vol. 12, no. 3, pp. 186-193, 2000.

[22] A. Gunasekaran, "Enablers of total quality management implementation in manufacturing: A case study," Total Quality Management, vol. 10, no. 7, pp. 987-996, 1999.

[23] A. K. Singh and Sushil, "Modeling enablers of TQM to improve airline performance," International Journal of Productivity and Performance Management, vol. 62, no. 3, pp. 250-275, 2013.

[24] M. Arif, A. Gupta, and A. Williams, "Customer service in the aviation industry - An exploratory analysis of UAE airports," Journal of Air Transport Management, vol. 32, pp. 1-7, 2013.

[25] Christianet, Total Quality Management Training, (accessed 21 February 2017), available at: http://www.christianet.com/ businesstraining/totalqualitymanagementtraining.htm.

[26] S.-H. Hsu and H.-P. Shen, "Knowledge management and its relationship with TQM," Total Quality Management and Business Excellence, vol. 16, no. 3, pp. 351-361, 2005.

[27] T. L. Ju, B. Lin, C. Lin, and H.-J. Kuo, "TQM critical factors and KM value chain activities," Total Quality Management and Business Excellence, vol. 17, no. 3, pp. 373-393, 2006.

[28] A. Rao, L. Car, I. Dambolena et al., Total Quality Management: A Cross-Functional Perspective, John Wiley and Sons, New York, NY, USA, 1996.

[29] S. Stough, S. Eom, and J. Buckenmyer, "Virtual teaming: A strategy for moving your organization into the new millennium," Industrial Management and Data Systems, vol. 100, no. 8, pp. 370-378, 2000.

[30] J. Saylor, TQM Simplified A Practical Guide, McGraw-Hill, New York, NY, USA, 1996.

[31] M. K. Verma, "Importance Of Leadership In Total Quality Management," in Vistas of Education, N. B. Biswas, Ed., pp. 6177, 1st edition, 2014.

[32] P. Tharmarajah, Total Quality Management in Aviation Maintenance, School of Aerospace, Mechanical and Manufacturing Engineering, RMIT University, Victoria, Australia, 2010.

[33] E. Sadikoglu and H. Olcay, "The effects of total quality management practices on performance and the reasons of and the barriers to TQM practices in turkey," Advances in Decision Sciences, vol. 2014, Article ID 537605, 17 pages, 2014.

[34] F. Talib and Z. Rahman, "Identification and prioritization of barriers to total quality management implementation in service industry: an analytic hierarchy process approach," TQM Journal, vol. 27, no. 5, pp. 591-615, 2015.

[35] K. Singh and I. S. Ahuja, "Implementing TQM and TPM paradigms in Indian context: Critical success factors and barriers," International Journal of Technology, Policy and Management, vol. 13, no. 3, pp. 226-244, 2013. 


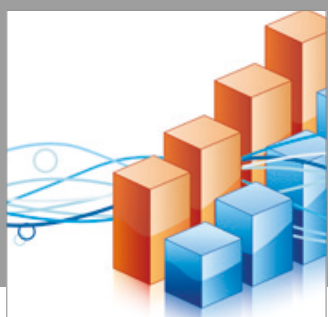

Advances in

Operations Research

vatersals

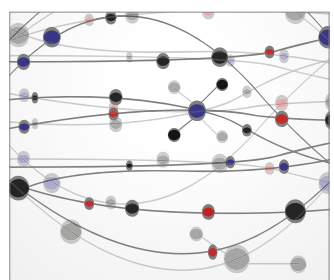

\section{The Scientific} World Journal
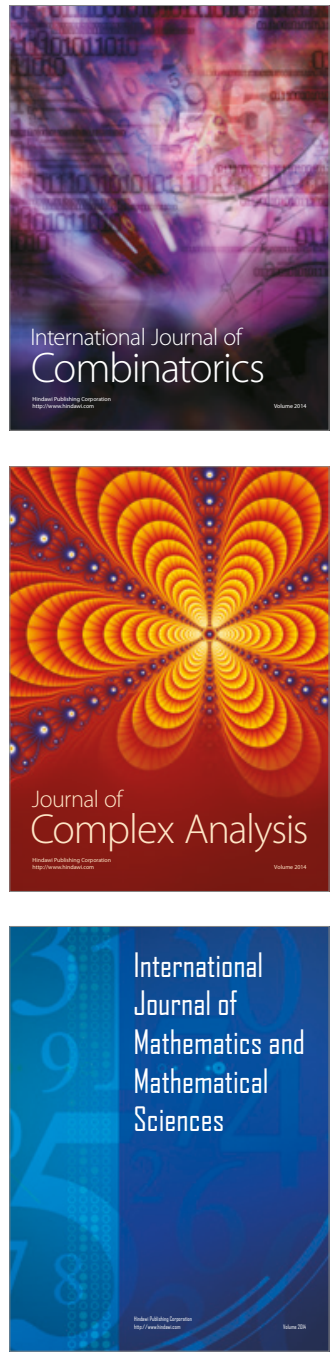
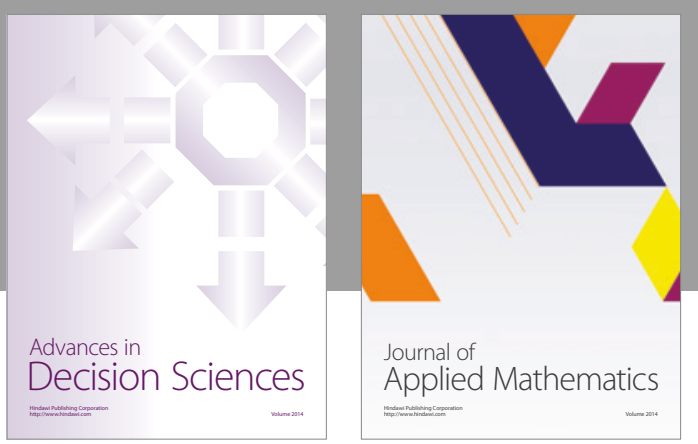

Algebra

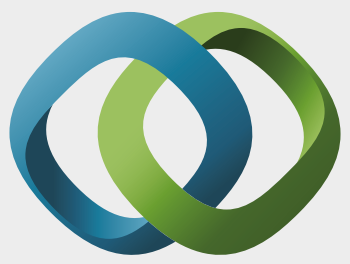

\section{Hindawi}

Submit your manuscripts at

https://www.hindawi.com
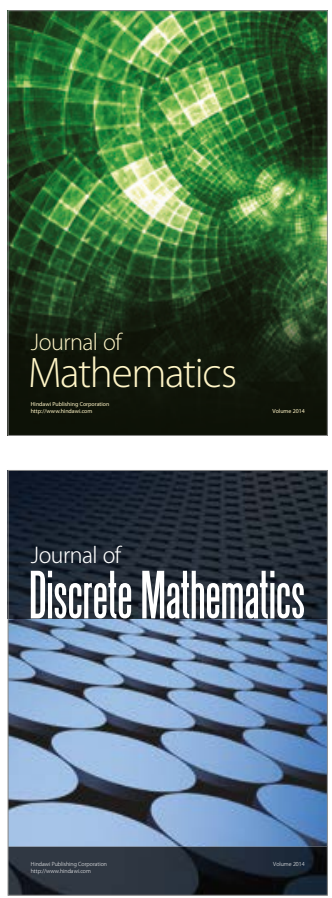

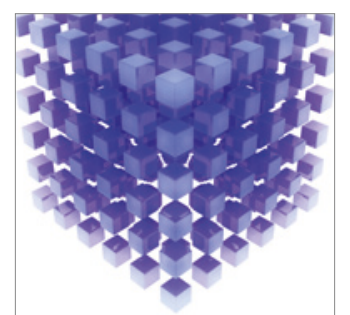

Mathematical Problems in Engineering
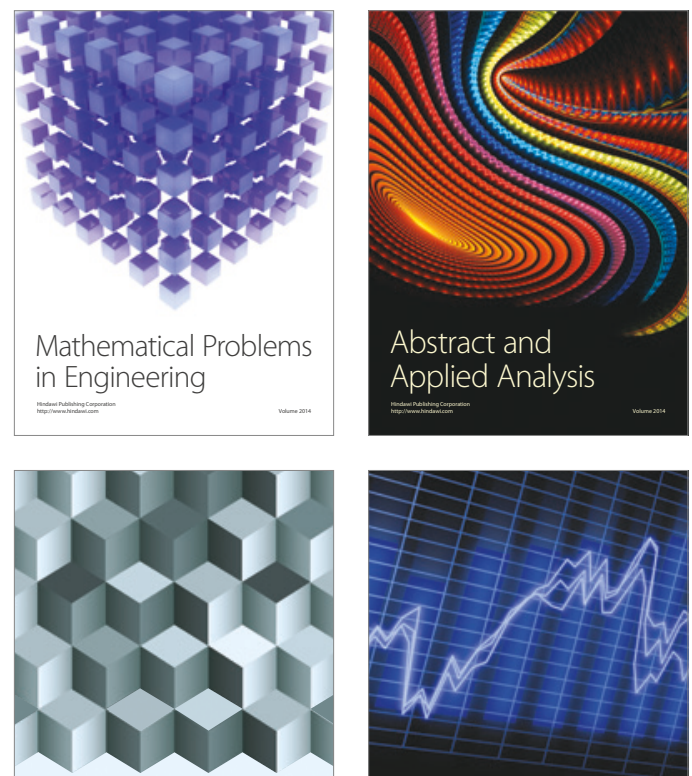

Journal of

Function Spaces

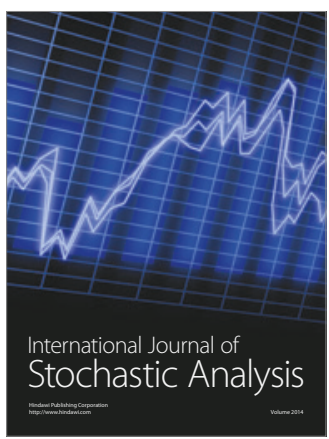

Probability and Statistics
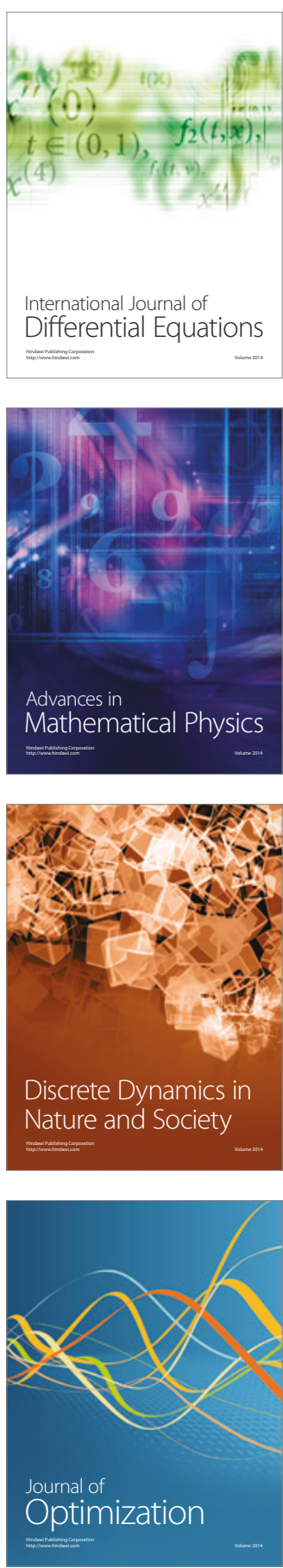